\title{
ОПТИМАЛЬНЕ (НА МНОЖИНІ МОДЕЛЕЙ І МЕТОДІВ ІДЕНТИФІКАЦЇ) ВИРІШЕННЯ ЗАДАЧІ ПРОГНОЗУВАННЯ ЧАСОВИХ РЯДІВ
}

На множині з 15 математичних моделей часових рядів та 4 методів їх ідентифрікації доведено доцільність оптимізації задачі прогнозування за відповідним критерієм якості прогнозу на розширеній методами ідентифрікації множині елементів, що оптимізуються.

\section{Критерії якості прогнозу.}

Показники економіки, як функції часу, можуть мати найрізноманітнішу структуру, довжину ряду, точність, тип прихованої закономірності розвитку (зміни) у часі, кроку по часу, інтервалу прогнозу та ін. Час $t$ представлено дискретами $t_{k}, k=0,1,2, \ldots$ не завжди з рівномірним кроком $\Delta t$ t. У випадку невідомої структури моделі ряду, перебираючи різні варіанти структур, можна підібрати найкращу (за основним критерієм $I$ (критерієм точності прогнозу) структуру. Моделі з степеневими елементами, як правило, краще використовувати для коротких рядів, а авторегресійні - для довгих (де не так сильно впливає невизначеність початкових умов). Фізично реалізуємий показник $\hat{I}$ точності прогнозу представимо взваженою сумою часткових показників $I_{i}(i=1,2,3)$, що відповідають за якість окремих властивостей моделі ряду. Показник $I_{1}$ :

$$
I_{1}=\frac{1}{n} \operatorname{tr}\left[\operatorname{diag} \frac{\left|\hat{\beta}_{i}^{\Pi}-\hat{\beta}_{i}^{H}\right|}{\left|\hat{\beta}_{i}\right|}\right], \quad i=\overline{1, n} ;
$$

де $-\hat{\beta}_{i}^{\Pi}, \hat{\beta}_{i}^{H} \mathbf{i} \hat{\beta}_{i}$ оцінки $i$-го параметра моделі, отримані по виборці парних, непарних та всіх дискретів $k$ часу $t_{k}$; це, так званий [1], параметричний показник регулярності. Показник :

$$
I_{2}=\left(\varepsilon^{T} \varepsilon\right) \cdot\left(x^{T} x\right)^{-1},
$$

де $\varepsilon^{E}=[\varepsilon(1), \cdots, \varepsilon(M)], \hat{x}^{T}=[\hat{x}(1), \cdots, \hat{x}(M)], \varepsilon(k)-$ похибки апроксимації сигналу $x(k)$ відповідною $\hat{x}(k)$ моделлю в $k$-ій точці ряду; це, так званий [1], показник незміщеності, або точності моделювання ряду моделлю. Показник $I_{3}$ :

$$
I_{3}=|1-K|, \quad K=\frac{\sum_{i=1}^{L} \eta_{i}|x(M-i) \cdot \hat{x}(M-i)|}{\sum_{i=1}^{L} \eta_{i}|x(M-i)| \cdot \sum_{i=1}^{L} \eta_{i}|\hat{x}(M-i)|} .
$$

(c) В.М. Мирунко, А.М. Сільвестров, 2005 
Тут $\eta_{i}$ - коефіціент розподілу бажаної точності прогнозу по $L$ останнім точкам вибірки $x(k), k=\overline{1, M} ; \sum_{i=1}^{L} \eta_{i}=1 ; \hat{x}(M-i)$ - прогнозні значення $x(M-i)$, отримані з моделі, побудованої на скороченій на $L$ останніх точок вибірці $k=\overline{1, M-L}$. Вважається, що прогнозований ряд $x(k)$ складається з прихованої детермінованої гладкої у часі складової і складової, близької до гаусівського “білого шуму”. Тому у варіаційному ряді упорядкованих по складності (мірності вектора $\beta$ невідомих параметрів) моделей, показники $I_{1}$ і $I_{3}$ обмежують мірність $n$ вектора $\beta$, в той час, як показник $I_{2}$ зі зростанням $n$ зменшуеться. Залежно від мети ідентифікації задаються коефріцієнти ваги $g_{i}$ взваженої суми цих трьох показників:

$$
\hat{I}=\sum_{i=1}^{3} g_{i} I_{i}, \sum_{i=1}^{3} g_{i}=1, g_{i} \geq 0 .
$$

Для задачі контролю параметрів $\beta_{i}$ моделі відомої структури максимальна вага $g_{1}$; для задачі точної апроксимації ряду $x(k)$ моделлю $\hat{x}(k)-g_{2}$; для задачі прогнозу $-g_{3}$. Сукупність показників $I_{1}, I_{2}, I_{3}$ забезпечуе компроміс між стабільністю оцінок моделі, точністю апроксимації та прогнозу.

На прикладі часового ряду, що має 43 дискрети $x(k)$ з рівномірним кроком $\Delta t=4$ місяці (один з показників у енергетиці України), (рис. 1), розглянемо рішення задачі прогнозу $x(k), k=\overline{1,37}$, на 6 останніх точок, вважаючи їх невідомими. Така постановка задачі дослідження дає можливість реалізувати, фрізично не реалізуемий при прогнозі в майбутне, об'єктивний показник $I$ відносної точності прогнозу на ці 6 точок, тобто відносне середньоквадратичне відхилення $\varepsilon(k)=\hat{x}(k)-x(k), k=\overline{38,43}$, прогнозних значень $\hat{x}(k)$ від відомих $x(k)$.

$$
I=\frac{[\varepsilon(38), \ldots, \varepsilon(43)] \cdot[\varepsilon(38), \ldots, \varepsilon(43)]^{T}}{[x(38), \ldots, x(43)] \cdot[x(38), \ldots, x(43)]^{T}}
$$

В критерії (3) взято $\eta_{i}=\frac{1}{L}=\frac{1}{6}$, в узагальненому критерії (4): $g_{1}=0.9$; $g_{2}=g_{3}=0.4$.

Далі слід визначити, наскільки показник (4), що реалізуеться, відповідає ідеальному (5), фізично не реалізуємому.

\section{Множина математичних моделей}

1. Моделі у вигляді степеневого поліному від дискретів $k$ часу:

$$
\begin{gathered}
\hat{x}(k)=\beta_{0}+\beta_{1} k, \\
\hat{x}(k)=\beta_{0}+\beta_{1} k+\beta_{2} k^{2}, \\
\hat{x}(k)=\beta_{0}+\beta_{1} k+\beta_{2} k^{2}+\beta_{3} k^{3}, \\
\hat{x}(k)=\beta_{0}+\beta_{1} k^{\frac{1}{4}}+\beta_{2} k^{\frac{1}{3}}+\beta_{3} k^{\frac{1}{2}}+\beta_{4} k^{\frac{3}{2}},
\end{gathered}
$$




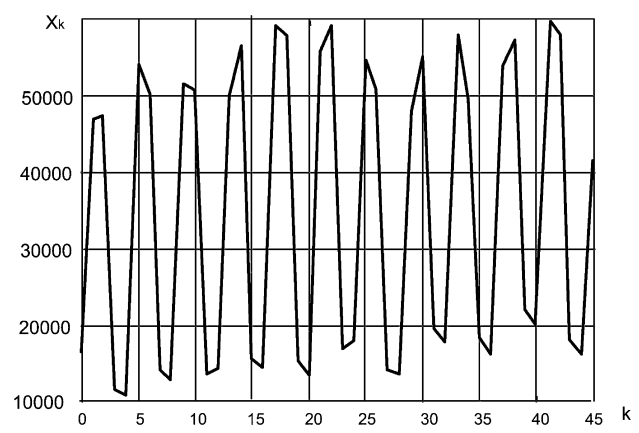

Рис. 1 - Часовий ряд.

$$
\hat{x}(k)=\beta_{0}+\beta_{1} k+\beta_{2} k^{-1}+\beta_{3} k^{-3},
$$

2. Моделі авторегресії від $k$ з постійним та змінним кроком:

$$
\begin{gathered}
\hat{x}(k)=\beta_{0}+\beta_{1} x(k-1), \\
\hat{x}(k)=\beta_{0}+\beta_{1} x(k-1)+\beta_{2} x(k-2), \\
\hat{x}(k)=\beta_{0}+\beta_{1} x(k-1)+\beta_{2} x(k-2)+\beta_{3} x(k-3), \\
x(k)=\beta_{0}+\beta_{1} x(k-4), \\
\hat{x}(k)=\beta_{0}+\beta_{1} x(k-1)+\beta_{2} x(k-2)+\beta_{3} x(k-3)+\beta_{4} x(k-4), \\
\hat{x}(k)=\beta_{0}+\beta_{1} x(k-1)+\beta_{2} x(k-4), \\
\hat{x}(k)=\beta_{0}+\beta_{1} x(k-1)+\beta_{2} x(k-4)+\beta_{3} x(k-8),
\end{gathered}
$$

3. Комбіновані поліноміально-авторегресійні моделі:

$$
\begin{gathered}
\hat{x}(k)=\beta_{0}+\beta_{1} k+\beta_{2} x(k-1), \\
\hat{x}(k)=\beta_{0}+\beta_{1} k+\beta_{2} x(k-4), \\
\hat{x}(k)=\beta_{0}+\beta_{1} k+\beta_{2} x(k-1)+\beta_{3} x(k-4) .
\end{gathered}
$$

Множина методів ідентифікації моделей (6-20).

1. Метод найменших квадратів (МНК). Оцінка $\hat{\beta}$ вектора $\beta$ параметрів моделей (6-20) знаходиться за умови: 


$$
\hat{\beta}=\arg \min _{\hat{\beta}}[\varepsilon(1), \cdots, \varepsilon(37)] \cdot[\varepsilon(1), \cdots, \varepsilon(37)]^{T},
$$

де $\varepsilon(k)=x(k)-\hat{x}(k), k=\overline{1,37}$.

2. Узагальнений МНК (УМНК). Оцінка $\hat{\beta}$ вектора $\beta$ параметрів моделей (6-20) знаходиться за умови:

$$
\hat{\beta}=\arg \min _{\hat{\beta}}[\tilde{\varepsilon}(1), \cdots, \tilde{\varepsilon}(37)] \cdot[\tilde{\varepsilon}(1), \cdots, \tilde{\varepsilon}(37)],
$$

де $\tilde{\varepsilon}(k)=\tilde{x}(k)-\hat{x}(k), k=\overline{1,37} ; \tilde{x}(k)$ - ковзне середне значення $x(k)$; $\tilde{x}(k)=\frac{1}{5} \sum_{i=k-2}^{k+2} x(k+i)$.

3. Інтегрований МНК (ІМНК). Оцінка $\hat{\beta}$ вектора $\beta$ параметрів моделей (6-20) знаходиться за умови:

$$
\hat{\beta}=\arg \min _{\hat{\beta}} \sum_{p=1}^{5}[\varepsilon(1), \cdots, \varepsilon(37-p)] \cdot[\varepsilon(p), \cdots, \varepsilon(37)]^{T},
$$

тобто за умови мінімуму суми зсунутих на $p$ дискрет $\Delta t$ часу добутків $\varepsilon(k)$ на $\varepsilon(k+p)$.

4. Метод допоміжної змінної (МДЗ). Оцінка $\hat{\beta}$ вектора $\beta$ параметрів моделей (6-20) визначається, як і МНК - оцінка (21), але замість фрунцції чутливості $\frac{\partial \varepsilon}{\partial \hat{\beta}}$ взято деяку допоміжну функцію $U$ з компонентами $U_{i}$. В нашому прикладі $U_{i}$ дорівнюе сигнум - функції від $\frac{\partial \varepsilon}{\partial \beta_{i}}$.

\section{Числовий експеримент}

На множині структур (6)-(20) моделей часового ряду (Рис. 1.) та множині методів (МНК, УМНК, ІМНК, МДЗ), перевірено ефективність використання фізично реалізуемого критерію (4) на предмет його близькості до фрізично не реалізуемого бажаного критерію (5). Під ефективністю тут розуміється правильність вибору найкращого за критерієм (5) методу, вибраного по критерію (4). Результати числового моделювання для моделей (6)-(20) представлено в 15 рядках таблиці. В стовпчиках 1-10 подано:

1 - типи моделей (степеневі (6)-(10), авторегресійні (11)-(17), комбіновані (18)-(20)); 2 - відносну середньо - квадратичну похибку моделювання ряду відповідною моделлю на $k=\overline{1,37}$ при ідентифікації їі по МНК; 3 фізично не реалізуємий ідеальний критерій (5) для моделі, отриманої по МНК; 4 - фрізично реалізуемий критерій (4) при ідентифікації моделі по МHК; 5 - найкращий по критерію (4) метод ідентифікації для відповідної до рядка моделі;

6 - значення ідеального критерію (5) для вибраного за реальним критерієм (4) методом і для відповідної до рядка моделі; 7 - значення критерію (4) для вибраного за ним найкращого методу ідентифікації для відповідної до рядка моделі; 8 - найкращий за ідеальним критерієм (5) метод ідентифрікації відповідної до рядка моделі; 9 - значення ідеального критерію 
(5) для найкращого за ним методу ідентифікації моделі відповідного рядка; 10 - значення реального критерію (4) для найкращого за критерієм (5) методу ідентифікації моделі відповідного рядка.

\section{Аналіз результатів експерименту}

1. На множині з 15-ти структур моделей і 4 методів ідентифікації для конкретного ряду (Рис.1) найкращою по ідеальному критерію (5) виявилась авторегресійна модель (17) зі змінним запізненням на $k-1, k-4$ i $k-8$ кроків; метод - МДЗ. За реальним критерієм (4) отримано той же результат (!). Взагалі, з 15 розглянутих випадків у 8 -ми оптимальний метод ідентифікації за реальним критерієм (4) було вибрано вірно (рядки 2 , $3,6,7,10,11,12,15$ таблиці), тобто він співпав з методом, вибраним по ідеальному критерію (5). В інших 7-ми випадках (рядки $1,4,5,8,9,13,14$ ) ідеальний показник (5) для методу, вибраного за реальним показником (4), несуттєво гірший за цей показник для оптимального за ідеальним показником методу (стовпчики 6 і 9).

2. По мірі ускладнення моделей (6), (7), (8), що є степеневими рядами, показник (2) (II стовпчик таблиці) середньо-квадратичної похибки апроксимації ряду (Рис.1) моделями (6)-(8) зменшується, що природно витікає з теореми Вейерштраса про апроксимацію рядами Тейлора. В той же час ідеальний критерій (5) точності прогнозу при ускладненні моделей погіршується (рядки 1,2,3 третього стовпчика таблиці). Це підтверджує необєктивність внутрішнього апроксимативного критерію (2), некоректність його використання для задачі прогнозу.

Таблиця

Результати моделювання

\begin{tabular}{|l|l|l|l|l|l|l|l|l|l|l|l|}
\hline & 1 & 2 & 3 & 4 & 5 & 6 & 7 & 8 & 9 & 10 & 11 \\
\hline 1 & 6 & 0,49 & 0,47 & 0,25 & УМНК & 0,41 & 0,242 & МДЗ & 0,363 & 0,26 & 1,3 \\
\hline 2 & 7 & 0,484 & 0,593 & 0,26 & ІМНК & 0,415 & 0,223 & ІМНК & 0,415 & 0,223 & 1,43 \\
\hline 3 & 8 & 0,476 & 0,883 & 0,41 & ІМНК & 0,38 & 0,2 & ІМНК & 0,38 & 0,2 & 2,32 \\
\hline 4 & 9 & 0,485 & 0,593 & 0,27 & УМНК & 0,43 & 0,226 & ІМНК & 0,365 & 0,235 & 1,62 \\
\hline 5 & 10 & 0,488 & 0,49 & 0,25 & ІМНК & 0,45 & 0,23 & УМНК & 0,425 & 0,237 & 1,15 \\
\hline 6 & 11 & 0,49 & 0,435 & 0,24 & УМНК & 0,42 & 0,235 & УМНК & 0,415 & 0,235 & 1,05 \\
\hline 7 & 12 & 0,62 & 0,58 & 0,28 & УМНК & 0,56 & 0,262 & УМНК & 0,558 & 0,262 & 1,04 \\
\hline 8 & 13 & 0,123 & 0,143 & 0,04 & МНК & 0,143 & 0,04 & МДЗ & 0,096 & 0,048 & 1,49 \\
\hline 9 & 14 & 0,133 & 0,1 & 0,03 & МНК & 0,1 & 0,03 & МДЗ & 0,088 & 0,126 & 1,13 \\
\hline 10 & 15 & 0,113 & 0,122 & 0,037 & МДЗ & 0,092 & 0,03 & МДЗ & 0,092 & 0,03 & 1,33 \\
\hline 11 & 16 & 0,131 & 0,103 & 0,034 & МДЗ & 0,091 & 0,031 & МДЗ & 0,091 & 0,031 & 1,13 \\
\hline 12 & 17 & 0,087 & 0,092 & 0,015 & МДЗ & 0,063 & 0,011 & МДЗ & 0,063 & 0,011 & 1,46 \\
\hline 13 & 18 & 0,488 & 0,47 & 0,245 & МДЗ & 0,489 & 0,225 & УМНК & 0,411 & 0,237 & 1,14 \\
\hline 14 & 19 & 0,132 & 0,108 & 0,035 & МНК & 0,108 & 0,035 & МДЗ & 0,081 & 0,038 & 1,33 \\
\hline 15 & 20 & 0,131 & 0,111 & 0,036 & МНК & 0,111 & 0,037 & МНК & 0,111 & 0,037 & 1 \\
\hline
\end{tabular}

3. Дещо інша ситуація має місце для авторегресійних і змішаних поліноміально-авторегресійних моделей (11)-(20). Тут, внаслідок регуля- 
ризуючої властивості МНК, коли змінні зашумлені, внутрішній критерій (2) середньо-квадратичної міри близькості на ділянці апроксимації і зовнішній, як ідеальний $(5)$, так і $(k=\overline{1,37})$ реальний (4) критерії стають достатньо сильно корельованими. Тобто для цього класу моделей менш критичне використання апроксимативного критерію (2) в задачі прогнозу в точки (38-43) по зашумленим даним в точках (1-37). Тут має місце саморегуляризація. Чим складніше авторегресія, тим гірше обумовленість інформаційної матриці МНК для точних даних. Але для зашумлених некорельованою перешкодою даних діагональні елементи цієї матриці збільшуються i, як результат, зменшуються (за модулем) МНК-оцінки коефріціентів моделі, тим самим спрощуючи (регуляризуючи за А.М. Тихоновим [2]) модель.

4. Зіставимо значення ідеального критерію (5) для моделей, отриманих по МНК (стовпчик 3) і одному з запропонованих методів (стовпчик 6) з оптимізацією по реальному критерію (4). 315 моделей тільки для моделі (18) показник (5) несуттево менший. Тобто тільки тут за критеріем (4) помилково замість МНК було вибрано МДЗ. В інших чотирнадцяти випадках метод, знайдений за умови мінімуму фізично реалізуемого критерію (4) точності прогнозу, дав кращі результати, ніж МНК, або такі ж, якщо по (4) вибирався, як кращий, МНК (стовпчики 6 і 3 таблиці).

5. В межах одного методу ідентифікації, наприклад, МДЗ (стовпчик 6 , рядки 10-13) розкид ідеального критерію (5) залежно від структури моделі складає від 0,063 до 0,489, що підтверджує актуальність вибору структури моделі.

В межах однієї, наприклад, оптимальної за критерієм (5) моделі (17), оптимізація рішення на множині з чотирьох методів (МНК, МДЗ, УМНК, IMНК) дає виграш в 1,5 рази $(0,092$ - для МНК і 0,063 - для МДВ, як оптимального методу). Це підтверджуе актуальність вибору методу ідентифікації.

6. В цілому оптимізація на множині методів і моделей дає суттевий виграш у точності прогнозу. Визначимо цей виграш, як відношення критерію (5) для моделі з коефіціентами, визначеними по МНК (стовпчик 3 таблиці) до значення того ж критерію (5) для тієї ж моделі, з коефіцієнтами, визначеними оптимальним по (5) методом (стовпчик 9 таблиці). В стовпчику 11 таблиці подано це відношення, що лежить у межах від 1 до 2,32 .

\section{Література}

1. Івахненко А.Г. Долгострочное прогнозирование и управление сложными системами. - К.: Техніка, 1975. - 312 с.

2. Тихонов А.Н., Арсенин В.Я. Методы решения некорректных задач. - М.: Наука, 1979.-286 с. 